\title{
Pharmacological Study on the Effect of the Aqueous Extract of Mangifera Indicaa Leaves on Vascular Activity of Diabetic Albino Rats
}

\author{
Hassan Helaly Abu Rahma ${ }^{1}$, Haredy Hassan Haredy ${ }^{*}$, Hoda khalifa Abd-Elhady ${ }^{2}$, Saleh \\ Mohamed Hussein ${ }^{3}$ and Ahmed Abdelnaser Ahmed ${ }^{1}$ \\ ${ }^{1}$ Pharmacology Department, Faculty of Medicine, Al-Azhar University, Assuit \\ ${ }^{2}$ Physiology Department, Faculty of Medicine, Al-Azhar University, Assuit \\ ${ }^{3}$ Food Science and Technology Department, Faculty of Agriculture, Al-Azhar University, Assuit
}

*Corresponding author: Haredy Hassan Haredy, E-Mail: dr_haredy74@yahoo.com

\begin{abstract}
Background: diabetes mellitus is the most common endocrine disease, which is considered one of the most important causes of morbidity and mortality worldwide. Diabetes can affect many different organ systems in the body and can lead to serious complications. These complications can be classified as microvascular or macrovascular. Microvascular complications include nervous system damage, renal system damage and eye damage. Macrovascular complications include cardiovascular disease, stroke and peripheral vascular disease. Objective: it aimed to assess effects of aqueous mango leaves extract on diabetes mellitus. Materials and Methods: aqueous mango leaves extract were assessed for their effects on blood glucose, blood pressure, lipid profiles and body weight in diabetic rats. Also, check out photochemical agents including total phenolics, flavonoids, tannins and antioxidant activity in the aqueous mango leaves extract. Results: aqueous mango leaves extract are rich in total phenols, flavonoides and tannins content, so the antioxidant activity is high. Random blood glucose level and systolic blood pressure were decreased in diabetic rats treated with either aqueous extract of mango leaves or glibenclamide, while, body weight was increased in diabetic rats treated with either glibenclamide or aqueous extract of mango leaves. The contractile responses to norepinephrine were decreased and the relaxant effect of acetylcholine were increased significantly in diabetic rats treated with either glibenclamide or aqueous extract of mango leaves. The treatment of glibenclamide with aqueous mango leaves extract gave the best results with diabetic rats compared to other treatments. Conclusion: aqueous mango leaves extract produced a significant hypoglycemic effect in diabetic rats and improved the diabetes mellitus induced changes in the vascular reactivity, so possibility of its using as dietary supplements have healthy and therapeutic properties.
\end{abstract}

Keywords: Aqueous mango leaves extract, Diabetes mellitus, Vascular reactivity.

\section{Introduction}

Diabetes mellitus (DM) is a combination of heterogeneous disorders commonly presenting with episodes of hyperglycaemia and glucose intolerance, as a result of lack of insulin, defective insulin action, or both ${ }^{(\mathbf{1})}$. DM leads to many complications like Peripheral vascular disease which may lead to bruises or injuries that do not heal, gangrene gangrene and ultimately amputation $^{(2)}$. Other complications include dental disease, reduced resistance to infections such as influenza and pneumonia, and macrosomia and other birth complications among pregnant women with diabetes. Although types of complications are similar for type 1 and type 2 diabetic patients, the frequency or timing of occurrence can vary ${ }^{(3)}$.

On the other hand, high glucose level was found to increase the production of free radicals, as determined by cell damage markers. Increased oxidative stress has been implicates in the pathogenesis of diabetic complications and reduced levels of antioxidants are found in blood and tissue in both human and experiments diabetes ${ }^{(4)}$. Herbal medicines and their preparations have been widely used traditionally, for the thousands of years in developing and developed countries owing to its natural origin and lesser side effects or dissatisfaction with the results of synthetic drugs. One of the characteristics of oriental herbal medicine preparations is that all the herbal medicines, either presenting as single herbs or as collections of herbs in composite formulae ${ }^{(5)}$. The traditional preparations comprise medicinal plants, minerals and organic matter. Herbal drugs constitute mainly 
those traditional medicines which primarily use medicinal plant preparations for therapy ${ }^{(6)}$.

Medicinal plants continue to provide valuable therapeutic agents, both in modern medicine and in traditional systems of medicine. Attention is being focused on the investigation of efficacy of plant based drugs used in the traditional medicine because they are economy, have a little side effects and according to WHO, about $80 \%$ of the world population depend mainly on herbal remedies $^{(7)}$. In developing countries of the world, most of the people depend on herbal medical care, as well as, In developed countries, traditional, complementary and alternative medicines are becoming more popular ${ }^{(8)}$. The use of medicinal plants and bioactive phytocompounds has seen more growing interest. The importance of a diet rich in polyphenols has long been sponsored and underlined because of their radical scavenging action, as well as anti-carcinogenetic properties ${ }^{(9)}$. Mangifera indica resides in most tropical biotopes in India, Southeast Asia, Malaysia, Himalayan regions, Sri Lanka, Africa, America and Australia ${ }^{(\mathbf{1 0})}$.

In Egypt, mango, Mangifera indica, is considered one of the most economic crops, where many local cultivars such as Alphonso, Baladi, and Ewaisi are successfully grown ${ }^{(\mathbf{1 1})}$. Mangifera indica contain alkaloids and glycosides which are of great importance pharmacologically ${ }^{(\mathbf{1 2})}$. Various parts of plant are used as an antiseptic, astringent, diaphoretic, stomachic, vermifuge, tonic, laxative and diuretic and to treat diarrhea, dysentery, anaemia, asthma, bronchitis, cough, hypertension, insomnia, rheumatism, toothache, haemorrhage and piles. Hypoglycemic effect of the aqueous extract of the leaves has been reported ${ }^{(\mathbf{1 3})}$. Mangiferin is a normal metabolite also to be found in mango leaves. In the Republic of Vietnam a technology has been elaborated, and subsequently improved, for obtaining Mangiferin from mango leaves ${ }^{(\mathbf{1 4})}$.

The predominant mechanism of mangiferin action is its antioxidant and free radical scavenging activity. The antioxidant activity is traceable already in the healthy condition, but it is strikingly amplified in the inflammatory and infectious states including diabetes $^{(\mathbf{1 5})}$. Mangiferin decreased diabeticenhanced lipid peroxidation products thiobarbituric acid reactive substances formed as degradation products of fats - down to the healthy level. Mangiferin shows exceptional antioxidant activity, stronger than cinnamon, and hepatoprotective activity against free radical-induced liver injury ${ }^{(\mathbf{1 6})}$. It also dosedependently inhibits inflammatory cytokines, tumor necrosis factor alpha (TNF $\alpha)$, nitric oxide (NO), and NF- $\mathrm{kBin}$ in vitro and in vivo experiments $^{(17)}$.

\section{Aim of the study:}

This study aims to assess the rule of aqueous extract from mango leaves on blood glucose, blood pressure, lipid profiles and body weight in diabetic rats.

\section{Materials and Methods \\ Materials:}

The following materials were used:

Acetylcholine (ACH) (Fluka, Switzerland); Glibenclamide (Sigma Chemical Company - Aldrich, USA); Mango leaves (Experimental Station Agriculture College, AlAzhar University, Assuit); Norepinephrine (NE) (Sigma Chemical Company, Aldrich, USA); Streptozotocin (STZ) (MP biomedicals, LLC- France).

\section{Experimental methods:}

Preparation of mango leaves extract: The leaves of Mangifera indica (Mango) were collected freshly from Experimental Station Agriculture College, Al-Azhar University, Assuit. The leaves were washed thoroughly with tap water, cut into small pieces; shade dried in air at room temperature and crushed to powder with an electric grinder. Ten gram of powdered sample and add $100 \mathrm{ml}$ boiling distilled water; then soaked for 15 minutes with stirring and left overnight. There after the infusion was filtered and the filtrate was freshly used $^{(\mathbf{8})}$.

Experimental animals: Adult male albino rats were chosen as an animal model for this study. Rats were brought from animal house, Faculty of Medicine, Assiut University, Assiut, Egypt, and were maintained on a balanced diet with water supply freely in clean containers. They were kept for two weeks to adapt to the laboratory conditions before the start of the experiment. Sixty age-matched male albino rats with initial body weights ranging from 150 to $200 \mathrm{~g}$ were used. The rats were divided into six groups (10 rats each). Group I: Normal untreated non diabetic rats received distilled water only (control). Group II: Normal rats treated with aqueous extract of mango leaves 
orally $\left(1 \mathrm{gm} / \mathrm{kg}\right.$ once/day ${ }^{(\mathbf{8})}$ for 8 weeks orally. Group III: Diabetic untreated rats (diabetes induced by single intra peritoneal injection with STZ) $(55 \mathrm{mg} / \mathrm{kg} \text { body wt. })^{(\mathbf{1 8})}$. Group IV: Diabetic rats treated with glibenclamide $(0.6$ $\mathrm{mg} / \mathrm{kg}$ once/day) ${ }^{(\mathbf{1 9 )})}$ for 8 weeks orally. Group V: Diabetic rats treated with aqueous extract of mango leaves $(1 \mathrm{gm} / \mathrm{kg} \text { once/day })^{(\mathbf{8})}$ for 8 weeks orally. Group VI: Diabetic rats treated with the aqueous extract of mango leaves $(1 \mathrm{gm} / \mathrm{kg}$ once/day $)+$ glibenclamide $(0.6 \mathrm{mg} / \mathrm{kg}$. once/day) for 8 weeks orally.

Induction of DM: The animals were injected by a single intra peritoneal injection of STZ $55 \mathrm{mg} / \mathrm{kg}$ body weight. Diabetes was confirmed through detecting blood glucose concentration 48 hours after STZ injection by glucose oxidase method using glucometer with glucose test strip (One Touch Basic) ${ }^{(20)}$. Animals having blood glucose concentration over $250 \mathrm{mg} / \mathrm{dl}$ were considered diabetic and selected for use ${ }^{(20)}$.

Drug administration: Glibenclamide was dissolved in distilled water to be given via gastric tube $(0.6 \mathrm{mg} / \mathrm{kg} / \mathrm{day}$ single dose for 8 weeks).

Aqueous extract of mango leaves: It was given in a single daily dose of $1 \mathrm{~g} / \mathrm{kg}$ body weight orally for 8 weeks.

Blood pressure measurement procedure: Rats were trained daily for the measurement of blood pressure (BP) by indirect rat tail cuff method (Harvard apparatus 520338). The system is an electronic version of the traditional sphygmomanometer cuff method used to determine blood pressure by noninvasive technique. Rats were placed ( $9 \mathrm{AM})$ in their maintenance cages for 2 hours. Afterward, systolic BP was measured in untrained animals. Once the rats were considered to be trained and not susceptible to stress from the tail-cuff procedure, systolic BP measurements were performed twice, before the beginning of the treatment regimen and after 8 weeks treatment at the same time of the day (11 AM).

Body weight: Body weight changes in all animals were recorded before the beginning of the treatment regimen and after 8 weeks from treatment.

\section{Collection of blood samples:}

A- The animal was anaesthetized with ether by placing the rat in an anesthetic box filled with ether vapor which was maintained by periodically applying liquid ether to a cotton wool on the base of the box. When surgical stage of anesthesia was reached (judged by loss of withdrawal reflexes), the animal was removed and placed on a table and blood was collected from the retro-orbital plexus using capillary tube $(0.75-1.0 \mathrm{~mm}$ internal diameter) inserted in the medial canthus medial to the eye globe for one touch method.

B- After eight weeks, blood was collected from carotid artery after sacrificing of animals. The blood was collected into a dry clean graduated glass centrifuge tube. It was rapidly set to centrifuge at 5000 r.p.m for 10 minutes about half of the supernatant serum was sucked out into a clean dry glass serology tube using Pasteur pipette.

Isolated aortic rings: On the day of experiment, animals were killed by a blow on the head and cutting the throat. Abdominal and thoracic walls were opened. The thoracic aorta was dissected and cut, placed in a dish containing Kreb's-Henseleit solution of the following composition (m mol/litre): $(\mathrm{NaCl}$ 118.4, $\mathrm{KCl} 4.69, \mathrm{kH}_{2} \mathrm{PO}_{4} 1.17, \mathrm{MgSO}_{4} 1.18, \mathrm{Ca}$ Cl 2.52, D-glucose 11.10 and $\mathrm{NaHCO}_{3}$ 25) aerated with carbogen (95\% oxygen and 5\% carbogen dioxide), put under the dissecting microscope, cleaned from the surrounding attached tissues and cut into small rings (about $4 \mathrm{~mm}$ length). The aortic ring was suspended in an isolated organ bath (30 ml capacity) containing Kreb, s-Henseleit solution maintained at $37^{\circ} \mathrm{C}$ and aerated with carbogen. Aortic rings were subjected to an initial tension $1 \mathrm{~g}$, and were kept in the organ bath (for equilibration) for approximately 90 minutes, the physiological solution was renewed every 15 minutes. Response of the aortic rings to drugs were measured isometrically with a Grass (FT O3) force-displacement transducer, and recorded on a polygraph. The viability and stability of the tissue was documented by a two equal contractile responses to the same concentration of norepinephrine $\left(10^{-7}\right)$. Norepinephrine is prepared and diluted in $1 \%$ $\mathrm{Hcl}$ solution to prevent auto-oxidation. Tissue were then washed several times and allowed to relax to the base line level. Cumulative doseresponse curves to norepinephrine were performed on each ring, diluted solutions of norepinephrine $\left(1 \times 10^{-8}\right.$ to $\left.1 \times 10^{-3}\right)$ were used. During performing the dose-response curves of norepinephrine each dose was added after reaching the plateau of the response of the previous dose. Each ring was serially washed after obtaining the maximum response and left 
to relax to reach the baseline. The response (force of contraction) of each dose is measured in mg tension. For relaxation study; aortic ring was precontracted by norepinephrine $\left(10^{-6}\right)$ sub maximal dose. When the response reached its plateau, cumulative concentration response curves of acetylcholine $\left(1 \times 10^{-8}\right.$ to $\left.1 \times 10^{-3}\right)$ was done and each ring was serially washed after obtaining the maximum response.

\section{Biochemical measurements:}

The blood glucose level was determined by enzymatic colorimetric method according to Trinder ${ }^{(21)}$. Total cholesterol (TC), Low density lipoprotein cholesterol (LDL-C) and High density lipoprotein cholesterol (HDLC) were evaluated from the serum as recommended by the National Cholesterol Education Program (NCEP) guidelines ${ }^{(22)}$ for lipid screening.

\section{Statistical analysis:}

Statistical analysis was done using the computer program (Prism). The quantitative data were presented in the form of mean \pm standard error (SE). One-way analysis of variance (ANOVA) was done to compare between the studied groups, followed by Students t-test to compare between each two means. A value of $\mathrm{P}<0.01$ was used as the limit for statistical significance.

\section{Approval and ethical statements}

The study protocol was approved by the local Ethical Committee of Pharmacology Department. Animals were lived in healthy weather and good diets, blood samples were taken under general anesthesia, and animals were scarified after general anesthesia.

\section{Results}

1. Effect of aqueous mango leaves extract on serum blood glucose, systolic blood pressure and body weight in diabetic rats:

In table (1) it could be noticed that, serum blood glucose and systolic blood pressure were increased significantly $(\mathrm{P}<0.01)$, while, body weight decreased significantly in the diabetic rats compared with the normal rats. On the other side, serum blood glucose and systolic blood pressure were significant differences $(\mathrm{P}<0.01)$ decreased, while body weight increased significantly in the diabetic rats treated with glibenclamide or aqueous mango leaves extract when compared with untreated diabetic rats, but the increase was below the weight of normal rats. No significant differences $(\mathrm{P}<0.01)$ between the effects of the glibenclamide with aqueous mango leaves extract on diabetic rats and the normal rats in serum blood glucose.

Table (1): Effect of aqueous mango leaves extract on serum blood glucose, systolic blood pressure and body weight in diabetic rats

\begin{tabular}{lccc}
\hline \multicolumn{1}{c}{ Groups } & $\begin{array}{c}\text { Serum blood glucose level } \\
(\mathbf{m g} / \mathbf{d l})\end{array}$ & $\begin{array}{c}\text { Systolic blood pressure } \\
(\mathbf{m m} / \mathbf{H g})\end{array}$ & Body weight (g) \\
\hline $\begin{array}{l}\text { Control normal } \\
\text { rats }\end{array}$ & $110.7 \pm 1.11$ & $112 \pm 2.7$ & $187.7 \pm 1.50$ \\
\hline $\begin{array}{l}\text { Control diabetic } \\
\text { untreated rats }\end{array}$ & $303.66 \pm 2.62 *$ & $155 \pm 1.8 *$ & $161.16 \pm 1.3 *$ \\
\hline $\begin{array}{l}\text { Normal rats with } \\
\text { MLE }\end{array}$ & $108.3 \pm 1.36 *$ \\
\hline $\begin{array}{l}\text { Diabetic rats with } \\
\text { glib. }\end{array}$ & $116.33 \pm 1.15 *$ & $107.2 \pm 1.4 *$ \\
\hline $\begin{array}{l}\text { Diabetic } \text { rats with } \\
\text { MLE }\end{array}$ & $134.42 \pm 1.21 *$ & $140.5 \pm 1.3 *$ & $179.7 \pm 1.1^{*}$ \\
\hline $\begin{array}{l}\text { Diabetic rats with } \\
\text { MLE }+ \text { glib. }\end{array}$ & $110.5522 \pm 1.34$ & $132.1 \pm 1.0 *$ & $175 \pm 1.6 *$ \\
\hline
\end{tabular}

Each value represents the mean \pm SE (standard error) of $7-9$ animals.

* Significant difference from control normal rats $(\mathrm{P}<0.01)$.

- Significant difference from control diabetic untreated rats $(\mathrm{P}<0.01)$.

MLE: Mango leaves extract.

\section{Effect of aqueous mango leaves extract on lipid profiles in diabetic rats \\ Our results (table 2) showed that} diabetes results in a significant increase $(\mathrm{P}<0.01)$ in TC and LDL-C compared with the normal rats, while, its decreased significantly in all diabetic rats treated with glibenclamide and aqueous mango leaves extract compared with the diabetic untreated rats. The highest reduction was achieved by using glibenclamide with aqueous mango leaves extract followed by diabetic rats treated aqueous mango leaves 
extract and diabetic rats treated with glibenclamide, respectively. On the other side, diabetic caused a significant decrease in HDLC compared with the normal rats, while, treating diabetic rats with glibenclamide and aqueous mango leaves extract caused a significant increase in the levels of HDL-C compared with the diabetic rats. The highest increase was achieved by using glibenclamide with aqueous mango leaves extract followed by diabetic rats treated with aqueous mango leaves extract and diabetic rats treated with glibenclamide, respectively as shown in Table 2 .

Table (2): Effect of aqueous mango leaves extract on lipid profiles in diabetic rats (mg/dl)

\begin{tabular}{|c|c|c|c|}
\hline Groups & $\mathbf{T C}$ & LDL-C & HDL-C \\
\hline Control normal rats & $82.35 \pm 1.02$ & $31.11 \pm 1.16$ & $51.47 \pm 1.37$ \\
\hline $\begin{array}{l}\text { Control diabetic } \\
\text { untreated rats }\end{array}$ & $100.83 \pm 1.12 *$ & $68.21 \pm 1.14^{*}$ & $32.13 \pm 1.06 *$ \\
\hline $\begin{array}{l}\text { Normal rats } \\
\text { with MLE }\end{array}$ & $81.15 \pm 1.06 *$ & $28.25 \pm 1.08 *$ & $53.13 \pm 1.23 *$ \\
\hline $\begin{array}{l}\text { Diabetic rats } \\
\text { with glib. }\end{array}$ & $99.21 \pm 1.32 *$ & $66.78 \pm 1.14 *$ & $49.26 \pm 1.41 *$ \\
\hline $\begin{array}{l}\text { Diabetic rats } \\
\text { with MLE }\end{array}$ & $83.32 \pm 1.22$ & $36.35 \pm 1.31 *$ & $46.92 \pm 1.65 *$ \\
\hline $\begin{array}{l}\text { Diabetic rats with MLE + } \\
\text { glib. }\end{array}$ & $82.72 \pm 1.50$ & $33.26 \pm 1.36 *$ & $49.34 \pm 1.29 *$ \\
\hline
\end{tabular}

Each value represents the mean \pm SE (standard error) of $7-9$ animals.

* Significant difference from control normal rats $(\mathrm{P}<0.01)$.

- Significant difference from control diabetic untreated rats $(\mathrm{P}<0.01)$.

MLE: Mango leaves extract.

\section{Effect of aqueous mango leaves extract on the contractile response to norepinephrine and the relaxant response to acetylcholine in diabetic rats aortae: \\ From tables (3) and (4) we noticed that,} norepinephrine induced contractile response of the rat aorta of the diabetic untreated rats was increased significantly $(\mathrm{P}<0.01)$ in comparison with the normal rats, the contractile response of the aorta of the diabetic rats treated with glibenclamide was decreased significantly $(\mathrm{P}<0.01)$ in comparison with the diabetic untreated rats, there is no significant difference $(\mathrm{P}<0.01)$ between contractile response of the aorta of the diabetic rats treated with glibenclamide in comparison with the normal rats. Results elicited by cumulative concentration-response curves elicited by acetylcholine on norepinephrine precontracted aortic ring preparations obtained from the normal rats, the diabetic untreated rats and the diabetic rats treated with glibenclamide for 8 weeks showed that the relaxant response of the aorta of the diabetic untreated rats was decreased significantly $(\mathrm{P}<0.01)$ compared with the normal rats, the rats treated with glibenclamide was increased significantly
$(\mathrm{P}<0.01)$ compared with the diabetic untreated rats, but there is significant decrease $(\mathrm{P}<0.01)$ compared with the normal rats.

Our results elicited by norepinephrine on aortic ring preparations obtained from the normal rats and normal rats treated with aqueous extract of mango leaves for 8 weeks, the diabetic untreated rats and the diabetic rats treated with aqueous extract of mango leaves for 8 weeks showed that the contractile response of the aorta was increased significantly in the diabetic untreated rats in comparison with the normal rats, and decreased significantly in the diabetic rats treated with aqueous extract of mango leaves in comparison with the diabetic untreated rats, with no significant difference between the response of the aorta of the normal rats treated with aqueous extract of mango leaves and the normal untreated rats aorta. The results showed that the relaxant response of the aorta to acetylcholine was decreased significantly in the diabetic untreated rats in comparison with the normal rats. Treatment with aqueous extract of mango leaves improved and increased significantly the relaxant effect of acetylcholine on the norepinephrine preconcentrated aorta.

Table (3): Effect of aqueous mango leaves extract on the contractile response in diabetic rats aortae to norepinephrine 
Pharmacological Study on the Effect of the Aqueous Extract of Mangifera Indicaa Leaves...

\begin{tabular}{|c|c|c|c|c|c|c|c|c|}
\hline $\begin{array}{ll}\text {-Log molar conc. } \\
\text { Groups }\end{array}$ & $1 \times 10^{-8}$ & $3 \times 10^{-8}$ & $1 \times 10^{-7}$ & $3 \times 10^{-7}$ & $1 \times 10^{-6}$ & $3 \times 10^{-6}$ & $1 \times 10^{-5}$ & $3 \times 10^{-5}$ \\
\hline Control normal rats & $0.0 \pm 0.00$ & $0.06 \pm 0.0$ & $0.3 \pm 0.03$ & $0.61 \pm 0.05$ & $0.89 \pm 0.06$ & $1.2 \pm 0.06$ & $1.6 \pm 0.05$ & $1.6 \pm 0.05$ \\
\hline $\begin{array}{l}\text { Control diabetic } \\
\text { untreated rats }\end{array}$ & $\begin{array}{c}0.61 \pm 0.0 \\
5^{*}\end{array}$ & $\begin{array}{l}0.94 \pm \\
0.03 *\end{array}$ & $\begin{array}{l}1.21 \pm \\
0.04^{*}\end{array}$ & $\begin{array}{c}1.45 \pm 0.06 \\
*\end{array}$ & $\begin{array}{c}1.80 \pm 0.09 \\
*\end{array}$ & $\begin{array}{c}2.12 \pm 0.0 \\
6^{*}\end{array}$ & $\begin{array}{l}2.52 \pm 0.08 \\
*\end{array}$ & $2.52 \pm 0.08^{*}$ \\
\hline $\begin{array}{ll}\text { Normal } & \text { rats } \\
\text { with MLE } & \end{array}$ & $0.0 \pm 00.01$ & $0.03 \pm 0.03 *$ & $0.26 \pm 0.04 *$ & $\begin{array}{c}0.58 \pm 0.04 \\
*\end{array}$ & $\begin{array}{c}0.86 \pm 0.06 \\
*\end{array}$ & $\begin{array}{c}1.15 \pm 0.0 \\
7\end{array}$ & $\begin{array}{c}1.48 \pm 0.09 \\
*\end{array}$ & $1.48 \pm 0.09 *$ \\
\hline $\begin{array}{l}\text { Diabetic with } \\
\text { MLE }\end{array}$ & $\begin{array}{c}0.40 \pm 0.0 \\
3 *\end{array}$ & $0.51 \pm 0.02 *$ & $\begin{array}{c}0.81 \\
\pm 0.04 * \\
\end{array}$ & $\begin{array}{c}1.12 \pm 0.05 \\
*\end{array}$ & $\begin{array}{c}1.41 \pm 0.07 \\
* \\
\end{array}$ & $\begin{array}{c}1.71 \pm 0.0 \\
4 * \\
\end{array}$ & $\begin{array}{c}2.11 \pm 0.04 \\
* \\
\end{array}$ & $2.11 \pm 0.04 *$ \\
\hline Diabetic with glib. & $\begin{array}{c}0.14 \pm 0.0 \\
2 *\end{array}$ & $\begin{array}{c}0.18 \pm 0.04 * \\
\text {. }\end{array}$ & $0.4 \pm 0.03 *$ & $0.8 \pm 0.03^{*}$ & $\begin{array}{c}1.12 \pm 0.04 \\
*\end{array}$ & $\begin{array}{c}1.44 \pm 0.0 \\
5 *\end{array}$ & $\begin{array}{c}1.88 \pm 0.06 \\
*\end{array}$ & $1.88 \pm 0.06 *$ \\
\hline $\begin{array}{l}\text { Diabetic with glib. } \\
+ \text { MLE }\end{array}$ & $\begin{array}{c}0.1 \pm 0.01 \\
*\end{array}$ & $0.15 \pm 0.03 *$ & $0.35 \pm 0.04 *$ & $\begin{array}{c}0.73 \pm 0.05 \\
*\end{array}$ & $\begin{array}{c}1.08 \pm 0.04 \\
*\end{array}$ & $\begin{array}{c}1.4 \pm 0.06 \\
*\end{array}$ & $\begin{array}{c}1.83 \pm 0.05 \\
*\end{array}$ & $1.83 \pm 0.05 *$ \\
\hline
\end{tabular}

Each value represents the mean \pm SE (standard error) of $7-9$ animals.

* Significant difference from control normal rats $(\mathrm{P}<0.01)$.

- Significant difference from control diabetic untreated rats $(\mathrm{P}<0.01)$.

MLE: Mango leaves extract.

Table (4): Effect of aqueous mango leaves extract on the relaxant response of the diabetic rats aortae to acetylcholine

\begin{tabular}{|c|c|c|c|c|c|c|c|c|}
\hline $\begin{array}{r}\text {-Log. molar } \\
\text { conc. of } \\
\text { (Ach) }\end{array}$ & $1 \times 10^{-8}$ & $3 \times 10^{-8}$ & $1 \times 10^{-7}$ & $3 \times 10^{-7}$ & $1 \times 10^{-6}$ & $3 \times 10^{-6}$ & $1 \times 10^{-5}$ & $3 \times 10^{-5}$ \\
\hline $\begin{array}{l}\text { Control } \\
\text { normal rats }\end{array}$ & $84.4 \pm 1.3$ & $73.0 \pm 1.2$ & $57.4 \pm 1.6$ & $43.0 \pm 1.0$ & $31.0 \pm 1.4$ & $27.6 \pm 1.8$ & $24.6 \pm 1.5$ & $24.6 \pm 1.4$ \\
\hline $\begin{array}{l}\text { Control } \\
\text { diabetic } \\
\text { untreated rats }\end{array}$ & $\begin{array}{l}100.0 \pm 0.0 \\
*\end{array}$ & $97.3 \pm 1.4 *$ & $86.2 \pm 1.5 *$ & $75.3 \pm 1.4 *$ & $68.5 \pm 1.7 *$ & $62.5 \pm 1.4 *$ & $57.1 \pm 1.4 *$ & $57.9 \pm 1.3 *$ \\
\hline $\begin{array}{l}\text { Normal with } \\
\text { MILE }\end{array}$ & $84.1 \pm 1.2^{*}$ & $72.2 \pm 1.0$ & $56.0 \pm 1.6$ & $42.4 \pm 1.3$ & $30.3 \pm 1.9 *$ & $26.6 \pm 1.6$ & $23.3 \pm 1.3$ & $23.2 \pm 1.2 *$ \\
\hline $\begin{array}{c}\text { Diabetic with } \\
\text { MLE }\end{array}$ & $95.3 \pm 1.1^{*}$ & $90.2 \pm 1.2^{*}$ & $\begin{array}{c}80.2 \pm 1.5^{*} \\
\end{array}$ & $70.4 \pm 1.3^{*}$ & $\begin{array}{c}63.2 \pm 1.6^{*} \\
\bullet\end{array}$ & $60.1 \pm 1.6^{*}$ & $55.0 \pm 0.0 *$ & $55.0 \pm 0.1^{*}$ \\
\hline $\begin{array}{c}\text { Diabetic with } \\
\text { glib. }\end{array}$ & $\begin{array}{l}91.5 \pm 0.4 \\
*\end{array}$ & $\begin{array}{l}84.0 \pm 1.5 \\
*\end{array}$ & $\begin{array}{c}68.0 \pm 1.3 \\
*\end{array}$ & $\begin{array}{l}54.4 \pm 1.3 \\
*\end{array}$ & $\begin{array}{c}42.0 \pm 1.6 \\
*\end{array}$ & $\begin{array}{l}39.8 \pm 1.8 \\
*\end{array}$ & $\begin{array}{c}38.2 \pm 1.3 \\
*\end{array}$ & $38.1 \pm 1.2^{*}$ \\
\hline $\begin{array}{c}\text { Diabetic with } \\
\text { MLE + glib. }\end{array}$ & $\begin{array}{l}88.9 \pm 1.1 \\
*\end{array}$ & $80 \pm 0.8 *$ & $66.7 \pm 1.2 *$ & $51.2 \pm 1.3^{*}$ & $39.5 \pm 1.7 *$ & $36.8 \pm 1.4$ & $34.6 \pm 1.2$ & $34.7 \pm 1.2$ \\
\hline
\end{tabular}

Each value represents the mean \pm SE (standard error) of $7-9$ animals.

* Significant difference from control normal rats $(\mathrm{P}<0.01)$.

- Significant difference from control diabetic untreated rats $(\mathrm{P}<0.01)$.

MLE: Mango leaves extract.

\section{Discussion}

Our results showed that, serum blood glucose and systolic blood pressure were increased significantly, while, body weight decreased significantly in the diabetic rats compared with the normal rats. On the other side, serum blood glucose and systolic blood pressure were significant difference decreased, while body weight increased significantly in the diabetic rats treated with glibenclamide or aqueous mango leaves extract when compared with untreated diabetic rats, but the increase was below the weight of normal rats. No significant differences between the effects of the glibenclamide with aqueous mango leaves extract on diabetic rats and the normal rats in serum blood glucose.

Results of our study are in agreement with the study of Ramya and Zaheda ${ }^{(23)}$ who reported that glibenclamide decreased glycated hemoglobin levels. Hassan et al. ${ }^{(24)}$ suggested that glibenclamide administration in diabetes was associated with significant increase in insulin levels and in lowering glucose tolerance curves. Wahba and Ebrahim ${ }^{(25)}$ showed that mango has a lot of vitamins and nutrients that help the body feel fuller. Jordan et al. ${ }^{(26)}$ and Menne et $\boldsymbol{a l} .{ }^{(27)}$ suggested that the dichloromethanic fraction of $M$. indica baroreflex mechanisms contribute to long-term 
control of sympathetic activity and blood pressure. The results of our study are in disagreement with the results obtained by Erejuwa $\boldsymbol{e t}$ al. ${ }^{(\mathbf{2 8 )})}$ who found that glibenclamide did not give any change in body weight of STZ diabetic induced rats. Also, Daad $\boldsymbol{e t}$ al ${ }^{\text {(29) }}$ found that glibenclamide treatment in diabetic rats had no significant change in mean arterial blood pressure.

diabetes results in our study showed that a significant increase in TC and LDL-C compared with the normal rats, while, its decreased significantly in all diabetic rats treated with glibenclamide and aqueous mango leaves extract compared with the diabetic untreated rats. The highest reduction was achieved by using glibenclamide with aqueous mango leaves extract followed by diabetic rats treated aqueous mango leaves extract and diabetic rats treated with glibenclamide, respectively. On the other side, diabetic caused a significant decrease in HDL-C compared with the normal rats, while, treating diabetic rats with glibenclamide and aqueous mango leaves extract caused a significant increase in the levels of HDL-C compared with the diabetic rats. The highest increase was achieved by using glibenclamide with aqueous mango leaves extract followed by diabetic rats treated with aqueous mango leaves extract and diabetic rats treated with glibenclamide, these results are in harmony with those obtained by Dineshkumar et $\boldsymbol{a l}^{\left({ }^{(30)}\right.}$ whom found that significant reductions in lipid variables after treatment with $M$. indica leaves extract due to its polyphenol compound in mangiferin which may be ascribed to lipid lowering activity or due to its influence on various lipid regulation systems.

Norepinephrine induced contractile response of the rat aorta of the diabetic untreated rats was increased significantly in comparison with the normal rats, the contractile response of the aorta of the diabetic rats treated with glibenclamide was decreased significantly in comparison with the diabetic untreated rats, there is no significant difference between contractile response of the aorta of the diabetic rats treated with glibenclamide in comparison with the normal rats. Results elicited by cumulative concentration-response curves elicited by acetylcholine on norepinephrine precontracted aortic ring preparations obtained from the normal rats, the diabetic untreated rats and the diabetic rats treated with glibenclamide for 8 weeks showed that the relaxant response of the aorta of the diabetic untreated rats was decreased significantly compared with the normal rats, the rats treated with glibenclamide was increased significantly compared with the diabetic untreated rats, but there is significant decrease compared with the normal rats. The results of our study are in agreement with the results obtained by other workers as; Karasu $\boldsymbol{e t}$ $\boldsymbol{a l} \mathbf{l}^{(31)}$ showed that the maximal contractile response of aorta to noradrenaline was augmented in STZ-diabetic rats. Also, Chan et $\boldsymbol{a l} .^{(32)}$ reported that glibenclamide may act on the endothelium to release nitric oxide and prostacyclin which primarily accounts for an endothelium-dependent relaxation. Nitric oxide released from the endothelium has been shown to diffuse into the underlying vascular smooth muscle and to stimulate cyclic guanosine monophosphate (cGMP) accumulation which mediates the nitric oxide-dependent relaxation. Elif and Mukadder ${ }^{(33)}$ showed that exposure of endothelium-intact rat aortic rings to glibenclamide raised the tissue content of cGMP by approximately two-fold and this rise was abolished in the presence of the nitric oxide synthase inhibitor. Wai-Kei $\boldsymbol{e t} \boldsymbol{a l}^{\mathbf{( 3 4 )}}$ observed that muscle relaxant effect of glibenclamide is a property additional to its pharmacological action as a selective blocker of potassium adenosine triphosphate (KATP) channels.

Our results elicited by norepinephrine on aortic ring preparations obtained from the normal rats and normal rats treated with aqueous extract of mango leaves for 8 weeks, the diabetic untreated rats and the diabetic rats treated with aqueous extract of mango leaves for 8 weeks showed that the contractile response of the aorta was increased significantly in the diabetic untreated rats in comparison with the normal rats, and decreased significantly in the diabetic rats treated with aqueous extract of mango leaves in comparison with the diabetic untreated rats, with no significant difference between the response of the aorta of the normal rats treated with aqueous extract of mango leaves and the normal untreated rats aorta. The results showed that the relaxant response of the aorta to acetylcholine was decreased significantly in the diabetic untreated rats in comparison with the normal rats. Treatment with aqueous extract of mango leaves improved and increased significantly the relaxant effect of acetylcholine on the 
norepinephrine preconcentrated aorta. These results are in agreement with Beltrán $\boldsymbol{e t} \boldsymbol{a l} .{ }^{(35)}$ who found that the aqueous $M$. indica extract induces a fall in blood pressure after intra venous injection. This effect most probably due to the increase of vasodilator action of acetylcholine. The direct relaxant effect of aqueous $M$. indica extract was observed by the reduction of the contractions induced by noreadrenaline in ring segments of mesenteric arteries.

\section{Conclusion}

Aqueous mango leaves extract produced a significant hypoglycemic effect in diabetic rats and improved the diabetes mellitus induced changes in the vascular reactivity.

\section{References}

1. Piero M, Nzaro G and Njagi J (2014): Diabetes mellitus- a devastating metabolic disorder. Asian J Biomedical Pharmaceutical Sci., 04 (40):1-7.

2. American Diabetes Association (2006): Diagnosis and classification of diabetes mellitus. Diabetes Care, 29:S43-S48.

3. American Association of Clinical Endocrinologists (2009): State of diabetes complications in America. Diabetes Care, 32(6):1119-1131.

4. Koleva I, Beek T and Linssen J (2002): Screening of plant extracts for antioxidant activity: a comparative study on three testing methods. Phytochemical Anal., 13:8-17.

5. Balammal G, Sekar B and Reddy J (2012): Analysis of Herbal Medicines by Modern Chromatographic Techniques. Inter J Preclin Pharm Rese., 3(1):50-63.

6. Pal $K$ and Shukla Y (2003): Herbal Medicine: Current Status and the Future. Asian Pacific J Cancer Prev., 4:281-288.

7. Patel P, Patel D and Patel N (2012): Experimental investigation of anti-rheumatoid activity of Pleurotus sajorcaju in adjuvantinduced arthritic rats. Chinese J Natur Medic., 10(4):269-274.

8. Nwinuka N, Monanu $M$ and Nwiloh $B$ (2008): Effects of aqueous extract of Mangifera indica L. stem bark on haematological parameters of normal albino rats. Pak J Nutr., 7(5):663-666.

9. Liu F, Fu S, Bi X, Chen F, Liao X and Hu $X$ (2013): Physico-chemical and antioxidant properties of four mango (Mangifera indica L.) cultivars in China. Food Chem., 138:396-405.
10. Calabrese F (1993): Frutticoltura tropicale e sub tropicale. Edagricole Bologna, 1:169-215. 11. El-Zohgbi $M$ and Mostafa $G$ (2002): Characterization of the geographic origin of mango pulp from Egypt, Brazil and Puerto Rico by ICP-MS. Zagazig J Agric Res., 28(3):629639.

12. Madunagu B, Ebana $R$ and Ekpe $E$ (1990): Antibacterial and Antifungal Activity of some medicinal plants of Akwa Ibom state. West Af J Biol Appl Chem., 35:25-30.

13. Shah K, Patel M, Patel $R$ and Parmar $R$ (2010): Pharmacognosy Review. Phcog Rev., 4:42-48.

14. Morsi R, EL-Tahan N And El-Hadad A (2010): Effect of aqueous extract $M$. indica leaves as functional foods. J Appl Sci Research, 6(6):712-721.

15. Pardo G, Sánchez C, Avila R, Yamamoto E and Revilla A (2006): Interaction of Vimang (Mangifera indica L. extract) with $\mathrm{Fe}$ (III) improves its antioxidant and cytoprotecting activity. Pharmacol Res., 54:389-395.

16. Pokorski M (2013): Mangiferin- A Nutraceutical with Clinical Implications. Vitam Miner., 2:e122.

17. Pokorski M, Rekawek A, Zasada I, Antosiewicz J and Delgado R (2012): Anti oxidation and the hypoxic ventilatory response. Adv Exp Med Biol., 758:373-380.

18. Campos M, Sánchez $M$ and Matute $C$ (2009): Molecular mechanisms of neuroprotection by two natural antioxidant polyphenols. Cell Calcium, 45:358-368.

19. Periyar $S$, Balu $P$, Sathiya $P$ and Murugesan K (2009): Antihyperglycemic effect of mangiferin in streptozotocin induced diabetic rats. J Health Sci., 55:206-214.

20. Arulselvan $P$ and Subramanian $S$ (2008): Ultrastructural and biochemical abnormalities in the liver of streptozotocin-diabetic rats: Protective effects of Murraya koenigii. J Pharm Toxi., 3:190-202.

21. Trinder $P$ (1969): Enzmatic cetermination of serum blood glucose. Ann Clin Biochem., 6:24-27.

22. Third Report of the National Cholesterol Education Program (NCEP) Circulation (2002): Expert panel on detection, evaluation and treatment of high blood cholesterol in adults (Adult treatment panel III) Final report. National Heart, Lung, and Blood Institute/National Institutes of Health. Circulation, 106(25):3143-421 
23. Ramya $R$ and Zaheda $B$ (2015): Comparative study of efficacy of glibenclamide versus metformin in newly diagnosed patients with type 2 diabetes mellitus. International $\mathbf{J}$ Pharma and Bio Sci., 6(4):370-377.

24. Hassan Z, Ahmed M, Yosof P, Naidu S, Kumar $G$ and Umachigi $S$ (2008): Hypoglycemic effect of aqueous extract of Gynura procumbens. Pharmacology, 30:50-7.

25. Wahba HM and Ebrahim Shimaa SF (2015): Study the Hypoglycemic Effect of Mongo Leaves Powder Fortified Balady Bread on Diabetic Rats Induced by Alloxan. World Appl Sci J., 33 (9):1402-1409.

26. Jordan J, Heusser $\mathbf{K}$, Brinkmann $J$ and Tank J (2012): Electrical carotid sinus stimulation in treatment resistant arterial hypertension. Autonomic Neurosc., 172:31-36. 27. Menne J, Jordan J, Linnenweber-Held S and Haller S (2013): Resistant hypertension: baroreflex stimulation as a new tool. Nephrol Dial Transpl., 28:288-295.

28. Erejuwa O, Sulaiman S, Wahab $M$, Sirajudeen K, Salzihan M, Salleh $S$ and Gurtu M (2010): Antioxidant protective effect of glibenclamide and metformin in combination with honey in pancreas of streptozotocininduced diabetic rats. Int J Mol Sci., 11:20562066.

29. Daad H, Magda M, Hanan $A$ and Omayma A (2012): Comparison between the effect of glibenclamide and captopril on experimentally induced diabetic nephropathy in rats. J Renin-Angiotensin-Aldosterone System, 14 (2):103-115.

30. Dineshkumar B, Mitra $A$ and Manyunatha $M$ (2010): Studies on the antidiabetic and hypolipidemic potentials of mangiferin (Xanthone Glucoside) in STZinduced type I and type II diabetic model rats. Int Adv Pharm Sci., 1:75-85.

31. Karasu C, Ozansoy G, Bozkurt O, Erdoğan D and Omeroğlu S (1997): Antioxidant and triglyceride-lowering effects of vitamin $\mathrm{E}$ associated with the prevention of abnormalities in the reactivity and morphology of aorta from streptozotocin-diabetic rats. Science J., 46(8):872-879.

32. Chan W, Yao X, Ko W and Huang Y (2000): Nitric oxide mediated endotheliumdependent relaxation induced by glibenclamide in rat isolated aorta. Cardiovasc Res., 46:180187.

33. Elif E and Mukadder Y (2005): Vaso relaxant effects of glibenclamide on rat thoracic aorta. Science J., 51(2):119-128.

34. Wai-Kei $\mathbf{C}$, Xiaoqiang $Y$, Wing-Hung $\mathrm{K}$ and Yu H (2000): Nitric oxide mediated endothelium-dependent relaxation induced by glibenclamide in rat isolated aorta. Cardiovascular Research, 46:180-187.

35. Beltrán A, Alvarez Y, Xavier F, Hernanz R, Rodriguez J and Núñez A (2004): Vascular effects of the Mangifera indica L. extract (Vimang). Eur J Pharm., 499: 297-305. 